\title{
The evidence of benefits of exercise training in interstitial lung disease: a randomised controlled trial
}

\author{
Leona M Dowman, 1,2,3,4 Christine F McDonald, 3,4,5 Catherine J Hill, ${ }^{2,4}$ \\ Annemarie L Lee, ${ }^{4,6}$ Kathryn Barker, $^{7}$ Claire Boote, ${ }^{7}$ lan Glaspole, ${ }^{8,9}$ \\ Nicole S L Goh, 3,4,8 Anne M Southcott, ${ }^{10}$ Angela T Burge, 1,4,6 Rebecca Gillies, 1,4 \\ Alicia Martin, ${ }^{7}$ Anne E Holland ${ }^{1,4,6}$
}

\begin{abstract}
- Additional material is published online only. To view please visit the journal online (http://dx.doi.org/10.1136/ thoraxjnl-2016-208638).
\end{abstract}

For numbered affiliations see end of article.

\section{Correspondence to} Leona M Dowman, La Trobe University/Alfred Health Clinical School, Level 4, The Alfred Centre, 99 Commercial Rd Prahran, VIC 3181, Australia; leona.dowman@austin.org.au

Received 15 March 2016 Revised 23 January 2017 Accepted 25 January 2017 Published Online First 17 February 2017

\section{SLinked}

- http://dx.doi.org/10.1136/ thoraxjnl-2016-209929

\section{ABSTRACT}

Background Uncertainty exists regarding the clinical relevance of exercise training across the range of interstitial lung diseases (ILDs).

Objective To establish the impact of exercise training in patients with ILDs of differing aetiology and severity. Methods 142 participants with ILD (61 idiopathic pulmonary fibrosis (IPF), 22 asbestosis, 23 connective tissue disease-related ILD (CTD-ILD) and 36 with other aetiologies) were randomised to either 8 weeks of supervised exercise training or usual care. Six-minute walk distance (6MWD), Chronic Respiratory Disease Questionnaire (CRDQ), St George Respiratory Questionnaire IPF-specific version (SGRQ-I) and modified Medical Research Council dyspnoea score were measured at baseline, 9 weeks and 6 months.

Measurements and main results Exercise training significantly increased 6MWD ( $25 \mathrm{~m}, 95 \% \mathrm{Cl} 2$ to $47 \mathrm{~m})$ and health-related quality of life (CRDQ and SGRQ-I) in people with ILD. Larger improvements in 6MWD, CRDQ, SGRQ-I and dyspnoea occurred in asbestosis and IPF compared with CTD-ILD, but with few significant differences between subgroups. Benefits declined at 6 months except in CTD-ILD. Lower baseline 6MWD and worse baseline symptoms were associated with greater benefit in 6MWD and symptoms following training. Greater gains were seen in those whose exercise prescription was successfully progressed according to the protocol. At 6 months, sustained improvements in 6MWD and symptoms were associated with better baseline lung function and less pulmonary hypertension.

Conclusions Exercise training is effective in patients across the range of ILDs, with clinically meaningful benefits in asbestosis and IPF. Successful exercise progression maximises improvements and sustained treatment effects favour those with milder disease.

Trial registration number Results, ACTRN12611000416998.

\section{INTRODUCTION}

Interstitial lung disease (ILD) is a disabling group of chronic lung conditions comprising over 200 different disease entities. ${ }^{1}$ They are typically associated with interstitial inflammation, ${ }^{2}$ and fibrosis as well as aberrant wound healing responses which appear to drive disease progression. ${ }^{3}$ The clinical

\section{Key messages}

What is the key question?

- Does the aetiology and severity of disease impact the response to exercise training in patients with interstitial lung disease (ILD) and is there an optimal time for exercise training to occur to achieve maximal benefit?

What is the bottom line?

- Exercise training delivers clinically meaningful improvements in exercise capacity and quality of life for patients across the range of ILDs, especially those with asbestosis and idiopathic pulmonary fibrosis, with more lasting effects in those with milder disease.

\section{Why read on?}

- This is the first study to establish the effect of disease aetiology and markers of severity on response to exercise training in ILD, providing high-quality evidence supporting the role of exercise training in the clinical management of all patients with ILD.

course is heterogeneous, but it is generally characterised by progressive morbidity ${ }^{2}{ }^{4}$ which can be chronic, irreversible and fatal. ${ }^{5} 6$ Distressing dyspnoea, profound fatigue and reduced exercise tolerance are common ${ }^{7}$ with consequent reductions in health-related quality of life (HRQoL). ${ }^{8}$ Pulmonary hypertension, skeletal muscle dysfunction, arrhythmia and exercise-induced hypoxaemia can further complicate the clinical picture. $^{7} 910$ Treatment options are often limited and patients may eventually require lung transplantation.

Exercise training offers promise as a beneficial therapy for patients with ILD, with improvements in six-minute walk distance (6MWD), dyspnoea, HRQoL and peak exercise capacity. ${ }^{11-13}$ Changes in 6MWD exceeded the minimal important difference (MID), suggesting benefits are clinically meaningful. ${ }^{11}$ Nonetheless, recommendations for exercise training in clinical guidelines remain weak. ${ }^{5} 6$ Existing randomised controlled trials 
(RCTs) are small with methodological limitations, particularly with regard to lack of blinding and loss to follow-up. There are opposing views regarding which patients benefit most ${ }^{14}{ }^{15}$ two studies suggest greater treatment effects in those with less functional impairment ${ }^{14}{ }^{16}$ while others ${ }^{15} 17$ found greater improvements in those with more severe impairment. Furthermore, it has been suggested that patients with idiopathic pulmonary fibrosis (IPF) may improve less from exercise training than patients with other disease aetiologies. ${ }^{11}{ }^{14}$ In an uncontrolled study ${ }^{14}$ patients with non-IPF ILD benefitted regardless of disease severity and were more likely to achieve longer-term symptomatic benefit than those with IPF. Therefore, the benefit of exercise training could vary according to disease severity and aetiology, and the timing of exercise training may matter for particular types of ILD.

Robust, adequately powered studies addressing the effects and timing of exercise training on ILD of different aetiologies are lacking. The primary aims of this study were to establish the impact of aetiology and severity of ILD on response to exercise training. The secondary aim was to identify an optimal time for exercise training to achieve maximal benefit.

\section{METHODS}

\section{Study design and participants}

This multicentre randomised, assessor-blinded, controlled trial, conducted at three tertiary hospitals in Melbourne, Australia, recruited patients with documented ILD who were clinically stable, ambulant, and reported dyspnoea on exertion despite maximal medical treatment (see online supplement). Exclusion criteria were concurrent and predominant respiratory disease other than ILD, a history of syncope on exertion, and any comorbidities that preclude exercise or participation in a supervised exercise programme within the previous 12 months. Participants were randomly allocated using consecutively numbered, sealed opaque envelopes to receive usual care or exercise training for 8 weeks. Randomisation was stratified according to four subgroups: IPF, dust-related ILD, connective tissue disease-related ILD (CTD-ILD) and other ILD. Those with IPF were further stratified for carbon monoxide transfer factor (TLCO) $\geq$ or $<40 \% .{ }^{5} 6$ A researcher independent of the study completed the block randomisation using a webbased sequence generator (http://www.randomization.com). The study was registered (ACTRN12611000416998) and the protocol published. ${ }^{18}$

\section{Intervention}

Participants in the intervention group attended a twice-weekly supervised outpatient exercise training programme consisting of $30 \mathrm{~min}$ of aerobic exercise, cycling and walking, plus upper and lower limb resistance training. ${ }^{18}$ Initial intensity for walking was $80 \%$ of peak walking speed achieved on the 6MWT, cycling at $70 \%$ of maximum work rate estimated from the 6MWT and resistance training at an initial load that corresponded to 10-12 RM (repetition maximum). ${ }^{18}$ Exercise was progressed weekly and a home exercise programme prescribed. Supplemental oxygen was provided during training if necessary to maintain $\mathrm{SpO}_{2} \geq 88 \%$ and used during home exercise in participants prescribed ambulatory oxygen. The exercise training was conducted within the hospitals' pulmonary rehabilitation (PR) programmes which also included an education component that was available and recommended to all participants. The control group received once weekly telephone calls for general support. A detailed description of the intervention is in the online supplement.

\section{Measurements}

The primary outcome measure was change in 6MWD. The secondary outcome measures were knee extensor and elbow flexor strength (hand held dynamometry ${ }^{19}$ ), HRQoL (Chronic Respiratory Disease Questionnaire (CRDQ) ${ }^{8}$ and St George Respiratory Questionnaire IPF specific version $\left(\right.$ SGRQ-I) ${ }^{20}$ ), dyspnoea (University of California San Diego Shortness of Breath Questionnaire (UCSD SOBQ) ${ }^{21}$ and Modified Medical Research Council dyspnoea (MMRC) scale ${ }^{22}$ ), anxiety and depression (Hospital Anxiety and Depression Scale (HADS) ${ }^{23}$ ) and global rating of change. These were assessed at baseline, 9 weeks and 6 months by an assessor blinded to group allocation. Spirometry, TLCO, lung volumes and echocardiographic assessment of pulmonary artery systolic pressure (PASP) were measured at baseline. Spirometry and TLCO were repeated at 6 months. Current comorbidities, the use of oxygen or pharmacological therapies were also documented (see online supplement).

\section{Statistical analysis}

Based on effects seen in our previous study, ${ }^{24} 22$ participants with dust-related ILD and 22 with CTD-ILD were required to detect a mean (SD) difference in $6 \mathrm{MWD}$ with $80 \%$ power between groups of $52(40) \mathrm{m}$ and 38 (30) $\mathrm{m}$ respectively. ${ }^{24}{ }^{25}$ For participants with IPF, to detect differences of 29 or $34 \mathrm{~m}$ (SD $43 \mathrm{~m}$ ) with $80 \%$ power, representing the upper and lower limits of the MID in $\mathrm{IPF}^{25}$ required 72 and 54 participants respectively. Patients with other ILD diagnoses were also recruited for a total of 142 participants. Data analysis was according to intention-to-treat (ITT) principles. Between-group differences were evaluated using linear mixed models with three fixed effects: group (exercise or control), time (baseline, 9 weeks and 6 months), and a group $\times$ time interaction. Baseline data were used as a covariate. Subgroup analyses were performed with addition of a subgroup category (IPF, dust-related ILD and CTD-ILD) and all possible interactions. Analysis of the other ILD subgroup was not performed as it represented a heterogeneous group of disease entities and not a distinct ILD subtype. Two per-protocol analyses were defined a priori including (1) those who completed the programme (attendance at 12 out of 16 sessions) $)^{24}$ and (2) those whose exercise training prescription was progressed according to the protocol. Categorical data were analysed using the Pearson $\chi^{2}$ test. Stepwise multiple linear regression was undertaken using backward elimination to identify independent predictors of change in 6MWD and symptoms. Receiver operating characteristic (ROC) curve analysis identified thresholds at which exercise training became less effective, using established MIDs for change in $6 \mathrm{MWD},{ }^{25}$ CRDQ dyspnoea and fatigue. ${ }^{26}$ All analyses were performed using SPSS V.20 (SPSS, Chicago, Illinois, USA). A p $<0.05$ was considered statistically significant. Further statistical details are described in the online supplement.

\section{RESULTS}

Between November 2011 and June 2014, 296 patients with ILD were screened and 142 were randomised (figure 1). Sixty-one participants had IPF, 22 had dust-related ILD (all asbestosis), 23 had CTD-ILD and 36 had other diagnoses (see online supplement). Forty-nine (66\%) participants in the intervention group completed the exercise programme. No adverse events occurred during exercise training. Follow-up data were available for $95 \%$ and $88 \%$ of participants at 9 weeks and 6 months respectively.

There were no baseline differences between the intervention and control groups for the entire ILD population, except for 
Figure 1 Flow of participants through the study. CTD-ILD, connective tissue disease-related ILD; HP, hypersensitivity pneumonitis; ILD, interstitial lung disease; IPF, idiopathic pulmonary fibrosis; NSIP, non-specific interstitial pneumonia.

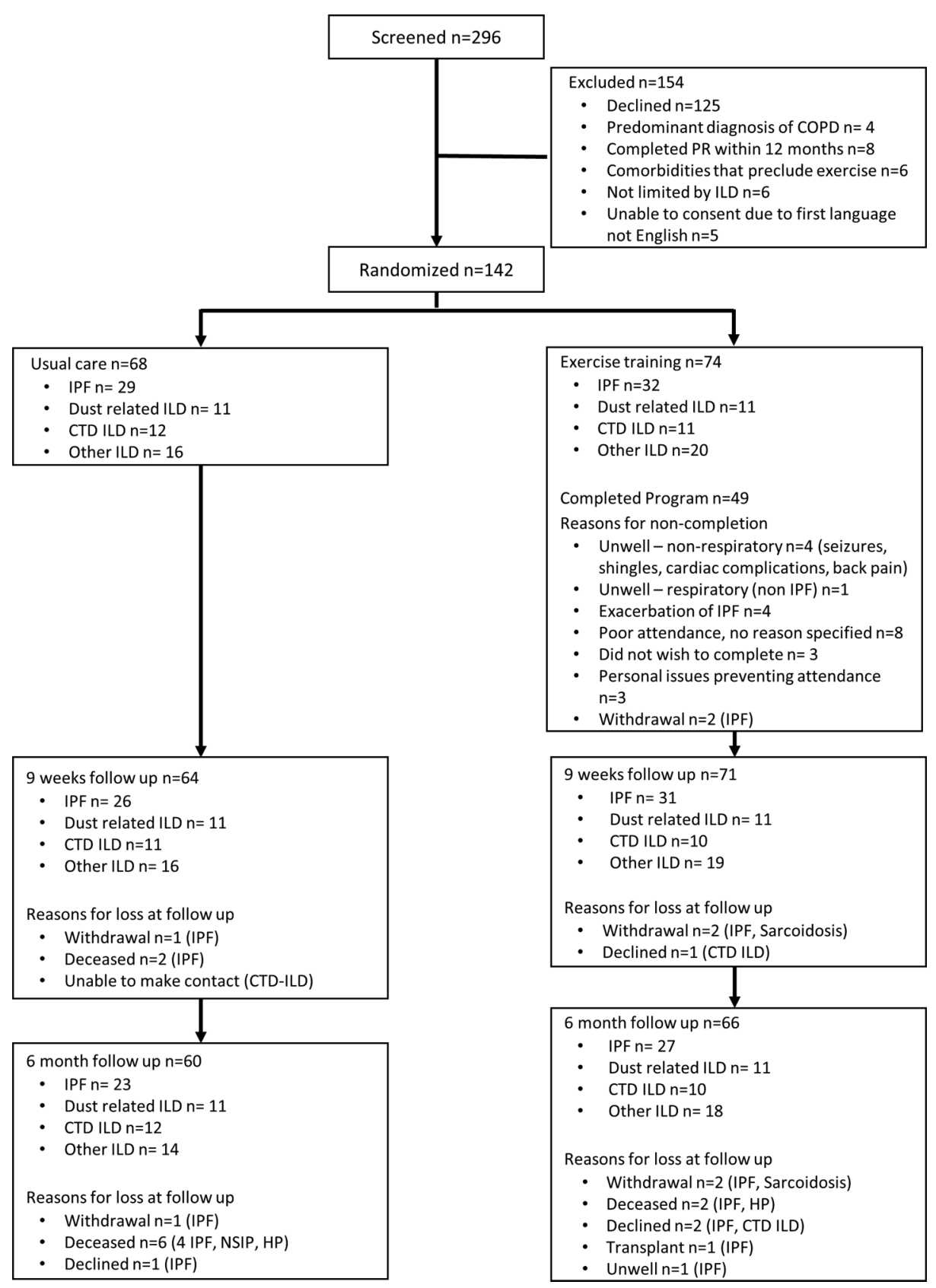

HRQoL and use of exertional oxygen (table E1, online supplement), or across subgroups, except for MMRC dyspnoea (table 1). Those with IPF had lower baseline 6MWD (mean (SD): $430(128) \mathrm{m}$ ) than those with asbestosis $(475(93) \mathrm{m})$ or CTD-ILD (505 (88) m, p=0.02). A small, non-significant, reduction in pulmonary function occurred at 6 months in the entire ILD population and the IPF subgroup (table 2). Twenty-seven (38\%) participants received supplemental oxygen during exercise training and $\mathrm{SpO}_{2}$ was maintained above $88 \%$ in 22 (81\%) participants. Home diary review revealed that 40 (54\%) participants in the intervention group achieved the three recommended home exercise sessions per week, averaging 2.4 sessions per week and 22 min per session. A similar pattern was demonstrated across the subgroups (table E2 in online supplement).

\section{Clinical outcomes: all ILD}

The 6MWD significantly improved following exercise training with a mean difference to control (95\% CI) of $25 \mathrm{~m}$ ( 2 to $47 \mathrm{~m}$ ). This improvement was not sustained at 6 months (table 3), with a significant decline in both groups (figure 2). The intervention group demonstrated significant short-term improvements in all CRDQ and SGRQ-I domains, except SGRQ-I impact score (table 3). A significant decline from 9 weeks to 6 months was seen in CRDQ mastery, SGRQ-I impact and SGRQ-I total in the exercise group (figures E1 and E2, online supplement). There was a trend towards reduced anxiety in the intervention group at 9 weeks $(p=0.06)$ that was lost at 6 months (figure E3a, online supplement). There was no significant change in depression (figure 3B, online supplement). Only $8 \%$ and $16 \%$ of participants respectively had clinically significant depression and anxiety at baseline (HADS score $\geq 11$ ). ${ }^{27}$ No significant differences between groups were evident for dyspnoea, knee extensor or elbow flexor strength (table 3). The global rating of change showed that perceived walking ability improved in 50\% of intervention participants and $17 \%$ in the control group following the intervention period $(\mathrm{p}<0.001)$, with a similar response for symptom improvement $(50 \%$ vs $12 \%, \mathrm{p}<0.001)$. 
Table 1 Baseline characteristics of participants for each subgroup

\begin{tabular}{|c|c|c|c|c|c|c|c|c|c|}
\hline & \multicolumn{3}{|l|}{ IPF } & \multicolumn{3}{|l|}{ Asbestosis } & \multicolumn{3}{|l|}{ CTD-ILD } \\
\hline & $\begin{array}{l}\text { Usual care } \\
n=29\end{array}$ & $\begin{array}{l}\text { Exercise training } \\
n=32\end{array}$ & $\mathrm{p}$ Value & $\begin{array}{l}\text { Usual care } \\
n=11\end{array}$ & $\begin{array}{l}\text { Exercise training } \\
\mathrm{n}=11\end{array}$ & $p$ Value & $\begin{array}{l}\text { Usual care } \\
\mathrm{n}=12\end{array}$ & $\begin{array}{l}\text { Exercise training } \\
n=11\end{array}$ & p Value \\
\hline Age (years) & $73(9)$ & $70(10)$ & 0.4 & $72(9)$ & $72(7)$ & 0.1 & $65(11)$ & $63(10)$ & 0.6 \\
\hline Gender, male & $20(69 \%)$ & $21(66 \%)$ & 0.8 & $11(100 \%)$ & $11(100 \%)$ & & $3(25 \%)$ & $1(9 \%)$ & 0.3 \\
\hline \multicolumn{10}{|l|}{ Oxygen therapy } \\
\hline Long term & $4(14 \%)$ & $2(6 \%)$ & 0.4 & $0(0 \%)$ & $0(0 \%)$ & & $1(8 \%)$ & $0(0 \%)$ & 1.0 \\
\hline Exertional & $10(35 \%)$ & $5(16 \%)$ & 0.1 & $2(18 \%)$ & $0(0 \%)$ & 0.2 & $1(8 \%)$ & $1(9 \%)$ & 1.0 \\
\hline \multicolumn{10}{|l|}{ Treatment } \\
\hline Prednisolone & $10(35 \%)$ & $5(16 \%)$ & 0.1 & $0(0 \%)$ & $0(0 \%)$ & & $6(50 \%)$ & $7(64 \%)$ & 0.7 \\
\hline Immunosuppressant & $3(10 \%)$ & $0(0 \%)$ & 0.1 & $0(0 \%)$ & $0(0 \%)$ & & $2(17 \%)$ & $5(46 \%)$ & 0.2 \\
\hline Pirfenidone & $1(3 \%)$ & $1(3 \%)$ & 1.0 & $0(0 \%)$ & $0(0 \%)$ & & $0(0 \%)$ & $0(0 \%)$ & \\
\hline Nintedanib & $0(0 \%)$ & $0(0 \%)$ & & $0(0 \%)$ & $0(0 \%)$ & & $0(0 \%)$ & $0(0 \%)$ & \\
\hline N-Acetylcysteine & $2(7 \%)$ & $0(0 \%)$ & 0.2 & $0(0 \%)$ & $0(0 \%)$ & & $0(0 \%)$ & $0(0 \%)$ & \\
\hline FVC (\%pred) & $78(19)$ & $74(18)$ & 0.4 & 78 (14) & $85(19)$ & 0.3 & $71(26)$ & $78(16)$ & 0.5 \\
\hline TLCO (\%pred) & $49(11)$ & $50(17)$ & 0.1 & $54(15)$ & $54(12)$ & 1.0 & $51(14)$ & $53(18)$ & 0.7 \\
\hline TLC (\%pred) & $77(13)$ & $75(15)$ & 0.6 & 80 (17) & $91(22)$ & 0.2 & 78 (17) & $82(19)$ & 0.7 \\
\hline PASP $(\mathrm{mm} \mathrm{Hg})$ & 37 (11) & $35(16)$ & 0.4 & $34(12)$ & $28(12)$ & 0.3 & $30(10)$ & $28(6)$ & 0.7 \\
\hline 6MWD (m) & $398(166)$ & $456(126)$ & 0.1 & $498(113)$ & $453(67)$ & 0.3 & $486(99)$ & $526(74)$ & 0.3 \\
\hline Knee extensor strength $(\mathrm{kg})$ & $19(7)$ & $21(6)$ & 0.2 & $24(7)$ & $20(4)$ & 0.05 & $18(5)$ & $20(5)$ & 0.5 \\
\hline MMRC dyspnoea & $2(1)$ & $2(1)$ & 0.3 & $2(0.7)$ & $1(0.5)$ & 0.5 & $2(0.7)$ & $1(0.4)$ & 0.04 \\
\hline Total CRDQ score & $83(23)$ & $83(22)$ & 1.0 & $82(15)$ & $90(21)$ & 0.3 & $87(16)$ & $96(19)$ & 0.2 \\
\hline Total SGRQ-I score & $55(19)$ & $49(18)$ & 0.2 & $53(17)$ & $45(17)$ & 0.3 & $48(20)$ & $41(16)$ & 0.1 \\
\hline UCSD SOBQ score & $47(20)$ & $39(23)$ & 0.2 & $41(19)$ & 37 (24) & 0.6 & $43(25)$ & $28(16)$ & 0.1 \\
\hline HADS anxiety & $6(4)$ & $6(4)$ & 0.9 & $7(2)$ & $6(4)$ & 0.4 & 8 (5) & $6(4)$ & 0.3 \\
\hline HADS depression & $6(4)$ & $5(3)$ & 0.2 & $5(3)$ & $6(3)$ & 0.7 & $6(3)$ & $4(3)$ & 0.3 \\
\hline \multicolumn{10}{|l|}{ Comorbidities } \\
\hline Hypertension & $11(38 \%)$ & $10(34 \%)$ & 0.6 & $6(55 \%)$ & $4(36 \%)$ & 0.7 & $6(50 \%)$ & $2(18 \%)$ & 0.2 \\
\hline Ischaemic heart disease & $8(28 \%)$ & $5(16 \%)$ & 0.4 & $2(18 \%)$ & $5(46 \%)$ & 0.4 & $0(0 \% 0$ & $0(0 \%)$ & \\
\hline Gastro-oesophageal reflux & $3(10 \%)$ & $8(25 \%)$ & 0.2 & $1(9 \%)$ & $0(0 \%)$ & 1.0 & $3(25 \%)$ & $2(18 \%)$ & 1.0 \\
\hline Osteoarthritis & $10(35 \%)$ & $10(31 \%)$ & 1.0 & $3(27 \%)$ & $3(27 \%)$ & 1.0 & $2(17 \%)$ & $2(18 \%)$ & 1.0 \\
\hline Rheumatoid arthritis & $1(3 \%)$ & $1(3 \%)$ & 1.0 & $0(0 \%)$ & $0(0 \%)$ & & $5(42 \%)$ & $5(46 \%)$ & 1.0 \\
\hline Diabetes & 10 (35\%) & $7(22 \%)$ & 0.4 & $4(36 \%)$ & $3(27 \%)$ & 1.0 & $1(8 \%)$ & $2(18 \%)$ & 0.6 \\
\hline Chronic back pain & $2(7 \%)$ & $3(9 \%)$ & 1.0 & $2(18 \%)$ & $1(9 \%)$ & 1.0 & $2(17 \%)$ & $0(0 \%)$ & 0.5 \\
\hline Obstructive sleep apnoea & $2(7 \%)$ & $4(13 \%)$ & 0.7 & $1(9 \%)$ & $0(0 \%)$ & 1.0 & $0(0 \%)$ & $0(0 \%)$ & \\
\hline COPD & $3(10 \%)$ & $1(3 \%)$ & 0.3 & $0(0 \%)$ & $0(0 \%)$ & & $1(8 \%)$ & $0(0 \%)$ & 1.0 \\
\hline Osteoporosis & $2(7 \%)$ & $1(3 \%)$ & 0.6 & $0(0 \%)$ & $0(0 \%)$ & & $1(8 \%)$ & $1(9 \%)$ & 1.0 \\
\hline
\end{tabular}

Values are mean (SD) or $\mathrm{n}(\%)$.

6MWD, six-minute walk distance; \%pred, per cent predicted; CRDQ, Chronic Respiratory Disease Questionnaire; CTD, connective tissue disease; HADS, Hospital Anxiety and Depression Scale; ILD, interstitial lung disease; IPF, idiopathic pulmonary fibrosis; MMRC, Modified Medical Research Council; PASP, pulmonary artery systolic pressure; SGRQ-I, St George Respiratory Questionnaire IPF specific version; TLC, total lung capacity; TLCO, carbon monoxide transfer factor; UCSD SOBQ, University College of San Diego Shortness of Breath Questionnaire.

Table 2 Change in pulmonary function over the duration of study

\begin{tabular}{|c|c|c|c|c|c|c|c|c|}
\hline & \multicolumn{4}{|l|}{ FVC \%pred } & \multicolumn{4}{|c|}{ TLCO \%pred } \\
\hline & Baseline & 6 months & Change & $\mathrm{p}$ Value & Baseline & 6 months & Change & p Value \\
\hline $\begin{array}{l}\text { ILD } \\
n=142\end{array}$ & $76.3(18.3)$ & 74.9 (19.7) & -1.4 & 0.1 & $50.7(14.9)$ & $50.3(16.5)$ & -0.4 & 0.6 \\
\hline $\begin{array}{l}\text { IPF } \\
\mathrm{n}=61\end{array}$ & 76.9 (17.4) & $75.4(20.3)$ & -1.6 & 0.3 & $49.5(15.0)$ & $48.5(16.5)$ & -1.0 & 0.5 \\
\hline Asbestosis $n=22$ & $76.4(20.0)$ & $81.5(16.5)$ & $5 \%$ & 0.09 & 54.5 (15.4) & $55.6(13.0)$ & 1.1 & 0.7 \\
\hline $\begin{array}{l}\text { CTD-ILD } \\
\mathrm{n}=23\end{array}$ & $75.5(22.0)$ & $78.9(20.4)$ & 0.3 & 0.08 & $53.6(15.8)$ & $54.7(17.2)$ & 1.1 & 0.6 \\
\hline
\end{tabular}

Impact of disease aetiology

The largest changes following the intervention occurred in those with asbestosis for 6MWD (figure 3), SGRQ-I (figure 4), all CRDQ domains except dyspnoea (figure E4, online supplement) and MMRC dyspnoea (figure E5, online supplement), followed by those with IPF, with the smallest 
Table 3 Differences between exercise and control groups following the intervention

\begin{tabular}{|c|c|c|c|c|c|}
\hline & \multirow{2}{*}{$\begin{array}{l}9 \text { week follow-up } \\
\text { Mean difference }(95 \% \mathrm{Cl})\end{array}$} & \multirow[b]{2}{*}{6 month follow-up } & \multicolumn{3}{|l|}{ p Value } \\
\hline & & & Group & Time & Group xtime \\
\hline 6MWD (m) & 25 (2 to 47 ) & $21(-3$ to 44$)$ & 0.03 & $<0.001$ & 0.7 \\
\hline Knee extensor strength $(\mathrm{kg})$ & $1.3(-0.1$ to 2.6$)$ & $0.8(-0.7$ to 2.2$)$ & 0.1 & 0.5 & 0.5 \\
\hline Elbow flexor strength (kg) & $0.3(-0.7$ to 1.3$)$ & $-0.2(-1.2$ to 0.8$)$ & 0.9 & 0.003 & 0.4 \\
\hline CRDQ Dyspnoea & $2.5(0.6$ to 4.3$)$ & $1.2(-0.7$ to 3.1$)$ & 0.02 & 0.7 & 0.2 \\
\hline CRDQ Fatigue & 2.6 (1.1 to 4.1$)$ & $1.4(-0.3$ to 2.9$)$ & 0.003 & 0.1 & 0.1 \\
\hline CRDQ Emotional function & $3.3(1.0$ to 5.6$)$ & $2.0(-0.3$ to 4.4$)$ & 0.008 & 0.2 & 0.3 \\
\hline CRDQ Mastery & 3.3 (1.4 to 5.2$)$ & $0.4(-1.5$ to 2.3$)$ & 0.02 & 0.004 & 0.01 \\
\hline SGRQ-I Symptoms & $-9.0(-15.4$ to -2.5$)$ & $-9.0(-15.5$ to -2.2$)$ & 0.001 & 1.0 & 1.0 \\
\hline SGRQ-I Activity & $-5.9(-11.2$ to -0.4$)$ & $-4.0(-9.5$ to 1.5$)$ & 0.04 & 0.8 & 0.5 \\
\hline SGRQ-I Impact & $-6.4(-11.4$ to -1.4$)$ & $0.6(-4.5$ to 5.7$)$ & 0.2 & 0.9 & 0.006 \\
\hline SGRQ-I Total & $-5.8(-9.7$ to -1.9$)$ & $-1.4(-5.4$ to 2.7$)$ & 0.04 & 1.0 & 0.04 \\
\hline UCSD SOBQ & $3.2(-2.7$ to 9.1$)$ & $-0.007(-6.0$ to 6.0$)$ & 0.6 & 0.01 & 0.2 \\
\hline MMRC dyspnoea scale & $-0.3(-0.5$ to 0.04$)$ & $-0.2(-0.5$ to 0.05$)$ & 0.06 & 0.6 & 1.0 \\
\hline
\end{tabular}

Figure 2 Change in six-minute walk distance. Data are raw mean (SE), ${ }^{*} p<0.05$, exercise versus control group, $+\mathrm{p}<0.05$, significant change over time, no significant group $\times$ time interaction.

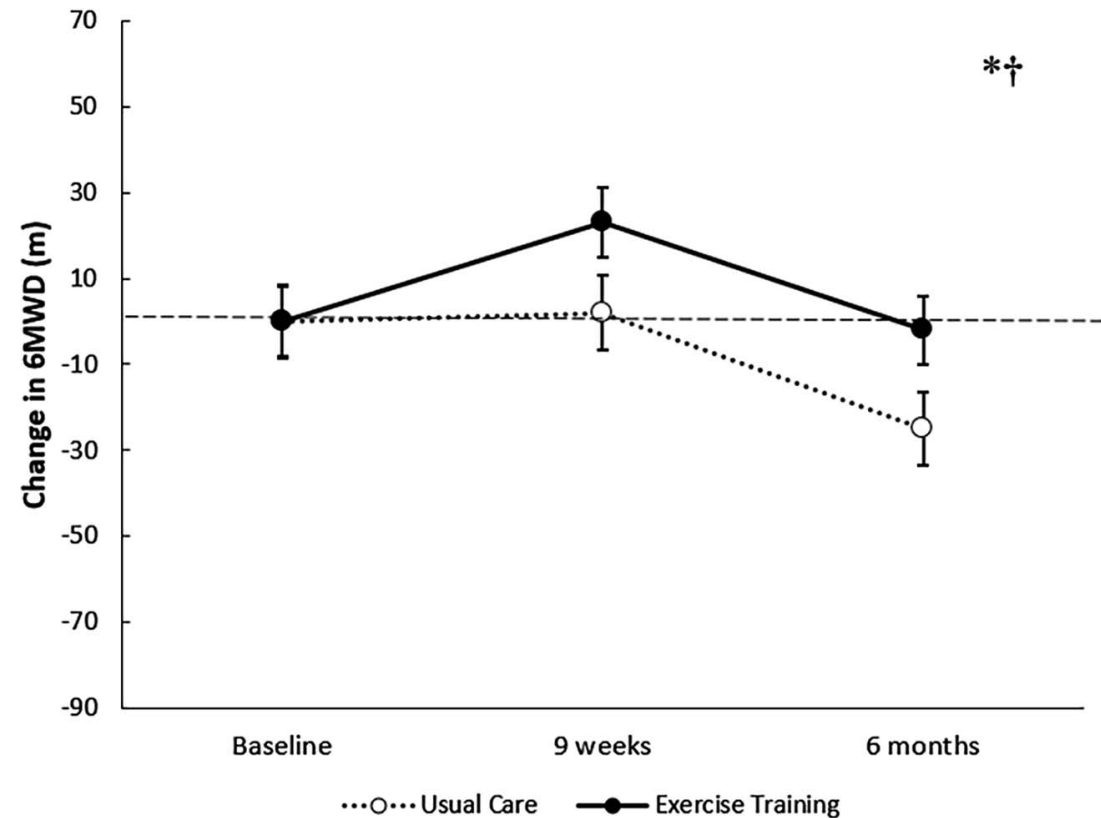

benefit often seen in those with CTD-ILD. Those with asbestosis and CTD-ILD had significantly greater improvements in the SGRQ-I symptoms compared with those with IPF (table 4). Regardless of group allocation, those with CTD-ILD had significantly better SGRQ-I impact and total scores at 9 weeks (table 4) and 6 months (figure 4). The 6MWD (figure 3) and CRDQ (figure E4, online supplement) improved at 6 months in those with CTD-ILD but declined in those with IPF and asbestosis; this different response over time reached significance only for CRDQ emotional function and mastery (table 4). There were no other significant differences between subgroups (table 4), including anxiety and depression (tables E3 and E4, online supplement). The CTD-ILD subgroup had a greater percentage of participants $(50 \%)$ who did not improve in 6MWD than those with IPF (30\%) and asbestosis (18\%), with a similar trend for CRDQ fatigue $(50 \%$ vs $33 \%$ vs $27 \%)$. There were no significant baseline differences between those who improved and those who did not improve in any subgroup.

\section{Programme completion and exercise progression}

A per-protocol analysis that included only those participants in the intervention group who completed the programme showed a greater increase in 6MWD (mean $27 \mathrm{~m}$ (95\% CI 2 to $52 \mathrm{~m}$, figure 5A). However, a per-protocol analysis including only those participants who were able to progress their exercise intensity according to the protocol showed a larger improvement in 6MWD $(37 \mathrm{~m}, 95 \%$ CI 11 to $64 \mathrm{~m}$, figure $5 \mathrm{~B})$. A similar pattern was demonstrated within diagnostic subgroups (table 5), and for HRQoL (table E5, online supplement). There were no significant differences between those who successfully completed the programme or progressed their exercise intensity and those who did not (table E6, online supplement). 

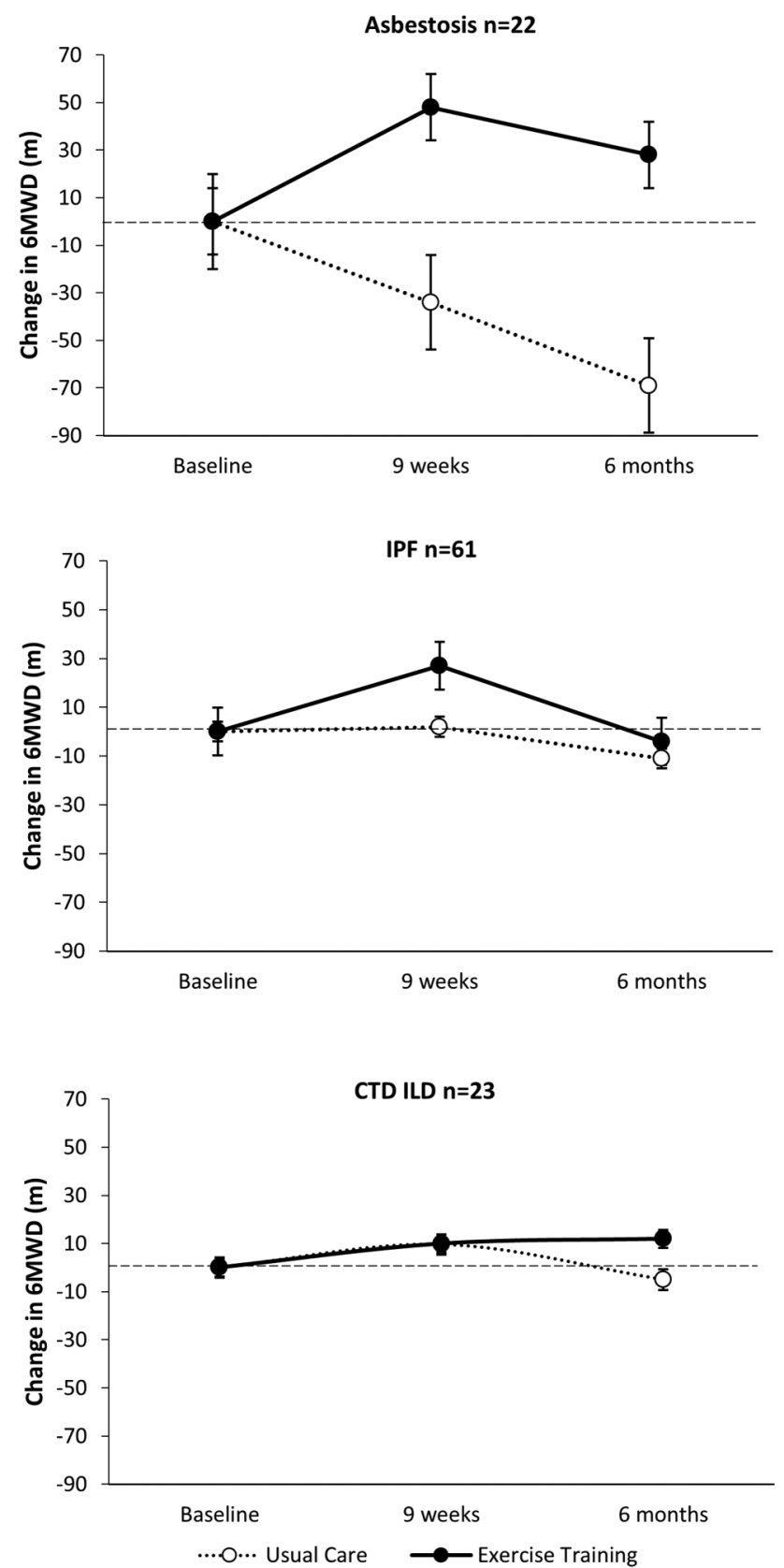

Figure 3 Change in six-minute walk distance for each subgroup. Data are raw mean (SE), no significant difference between subgroups or subgroup $\times$ group $\times$ time interactions.

\section{Predictors of response to exercise}

In a stepwise multiple regression model that included subgroup, group allocation and baseline variables with a significant relationship to change in 6MWD (table E7, online supplement), lower baseline $6 \mathrm{MWD}$ and allocation to exercise training predicted greater improvement in 6MWD at 9 weeks (table 6). For every $10 \mathrm{~m}$ increase in baseline $6 \mathrm{MWD}$, the gain in $6 \mathrm{MWD}$ at 9 weeks declined by $1.4 \mathrm{~m}$. Better physiological markers of disease severity predicted long-term gains in $6 \mathrm{MWD}$, with no effect of group allocation. For every $10 \mathrm{~mm} \mathrm{Hg}$ decrease in PASP or $100 \mathrm{~mL}$ increase in FVC, 6MWD increased at 6 months by 15 or $2.1 \mathrm{~m}$ respectively. These models explained $15 \%$ and $13 \%$ of the variation in exercise response at 9 weeks and 6 months respectively (table 6). A similar pattern was seen for change in symptoms (table E8, online supplement).
The ROC curve analysis indicated a baseline 6MWD threshold of $477 \mathrm{~m}$ above which exercise training was less likely to achieve 6MWD improvements exceeding the $\mathrm{MID}^{27}$ (sensitivity $75 \%$, specificity 55\%, area under the curve (AUC) 67\%, $\mathrm{p}=0.005$ ). A PASP threshold $\geq 31.5 \mathrm{~mm} \mathrm{Hg}$ predicted less likelihood of achieving the MID at 6 months (sensitivity $76 \%$, specificity $54 \%$, AUC $63 \%, \mathrm{p}=0.05$ ). A PASP $\geq 31.5 \mathrm{~mm} \mathrm{Hg}$ $(\mathrm{p}=0.001)$ also predicted, with better accuracy, less impact of exercise training on CDRQ fatigue (figure E6, online supplement). The ROC analysis could not identify a suitable threshold for lung function to predict long-term outcome in 6MWD or symptoms. The CTD-ILD and the IPF subgroup, respectively, had the greatest percentage of participants above the 6MWD (78\%) and the PASP (55\%) thresholds (see online supplement).

\section{DISCUSSION}

This is the largest RCT of exercise training in ILD and the first to establish the impact of aetiology and disease severity on response to exercise training. We demonstrated clinically important improvements in 6MWD, symptoms and HRQoL following exercise, strengthening previous findings ${ }^{11-13}$ and providing convincing evidence for exercise training to be adopted as a recommended treatment for all patients with ILD. We confirmed that people with asbestosis and IPF, and to a lesser extent CTD-ILD, receive clinically meaningful benefits and that disease severity predicts long-term benefit with sustained treatment effects favouring milder disease. A further novel finding was that successful adherence to exercise progression maximises the benefits.

The overall mean 6MWD improvement of $25 \mathrm{~m}$ was smaller than the MID $(30-33 \mathrm{~m})$ for people with $\operatorname{ILD}^{25}$ and smaller than previously reported, $(35 \mathrm{~m})^{24}$ despite equivalent disease severity and proportion of IPF participants. This could be attributed to the greater proportion of participants with CTD-ILD who experienced minimal change in 6MWD. Nonetheless improvements in CRDQ dyspnoea, fatigue and emotional function exceeded the MID. ${ }^{26}$ The MID for the SGRQ-I-specific version has not been established; however, improvements in SGRQ-I symptoms and activity exceeded the MID for the standard SGRQ for IPF. ${ }^{28}$ Together with the global rating of change scores, this suggests the impact of exercise training on health status was clinically significant and improvements were important to patients.

Despite the known diversity between ILD subgroups, the exercise response was not decidedly heterogeneous. Improvements achieved in those with asbestosis exceeded the MID for 6MWD, ${ }^{25}$ symptoms and HRQoL ${ }^{26} 2829$ and were comparable to previous reports in a combined cohort of dust-related pleural and interstitial respiratory diseases. ${ }^{13}$ Participants with IPF experienced smaller gains, in accordance with previous investigations ${ }^{11} 14{ }^{24}$ but improvements achieved fell within the MID range for $6 \mathrm{MWD}^{25}$ and exceeded the MID for HRQoL, ${ }^{26}{ }^{28}$ suggesting that exercise training is equally effective in IPF. The mean $6 \mathrm{MWD}$ improvement of $31 \mathrm{~m}$ was less than previously reported (46 and $81 \mathrm{~m}),{ }^{12}{ }^{30}$ however this could be attributed to the lack of blinding and ITT analyses in these studies, resulting in an overestimation of treatment effect. Additionally, our study may not have been optimally powered for IPF, as we did not achieve the larger sample size needed to detect mean effects equivalent to the lower estimates of the MID for 6MWD. Despite the limited improvement in those with CTD-ILD, some symptomatic benefit was achieved with changes in CRDQ dyspnoea and SGRQ-I symptoms exceeding 
Figure 4 Change in health-related quality of life (St George Respiratory Questionnaire IPF specific version, SGRQ-I) for each subgroup. Data are raw mean $(\mathrm{SE}),{ }^{*} \mathrm{p}<0.05$, significant difference between subgroups, no significant subgroup $\times$ group $\times$ time interactions, a reduction in scores represents an improvement.

\section{A Symptoms}
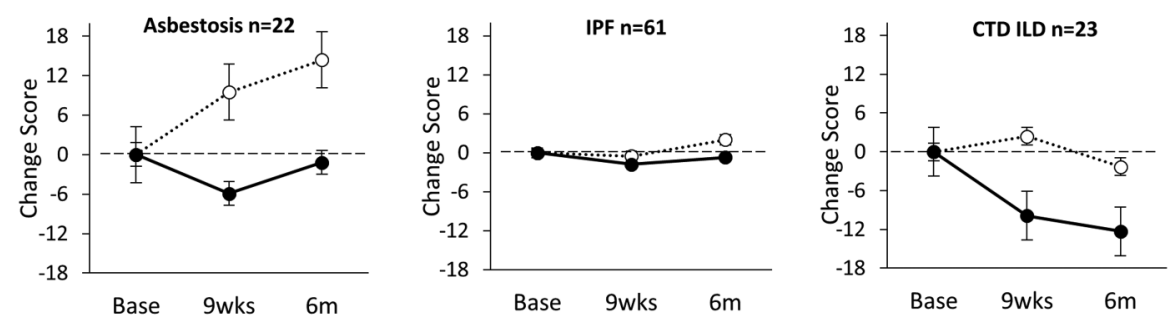

B Activity
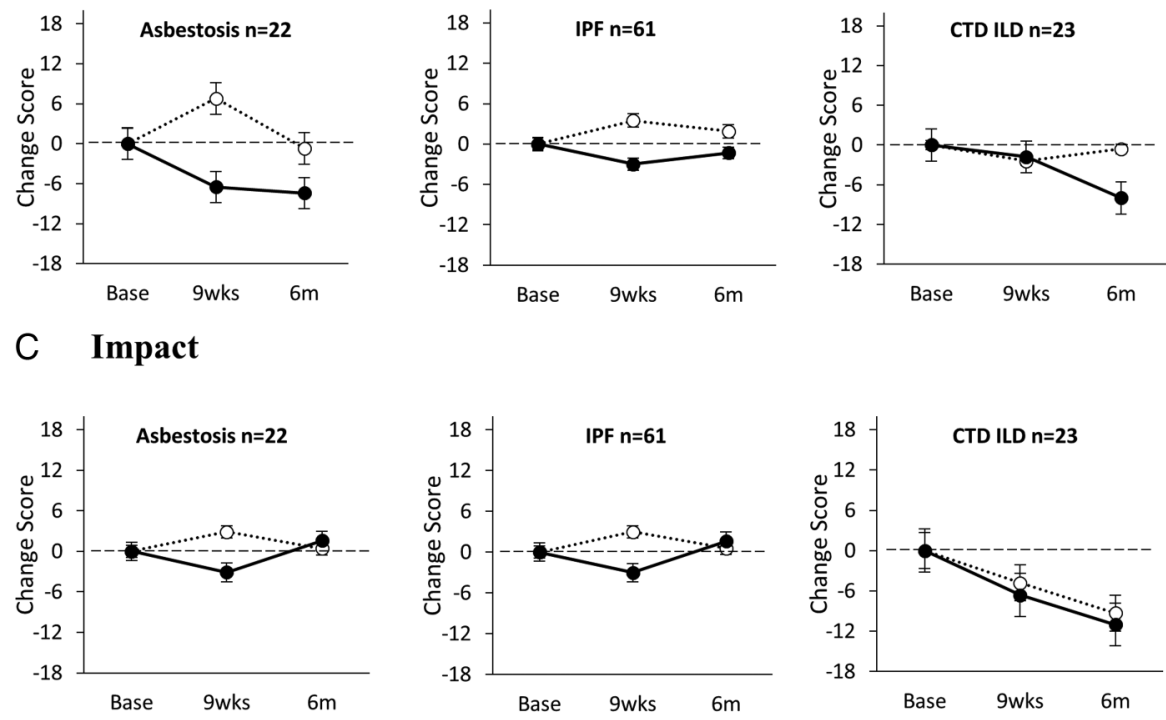

D Total
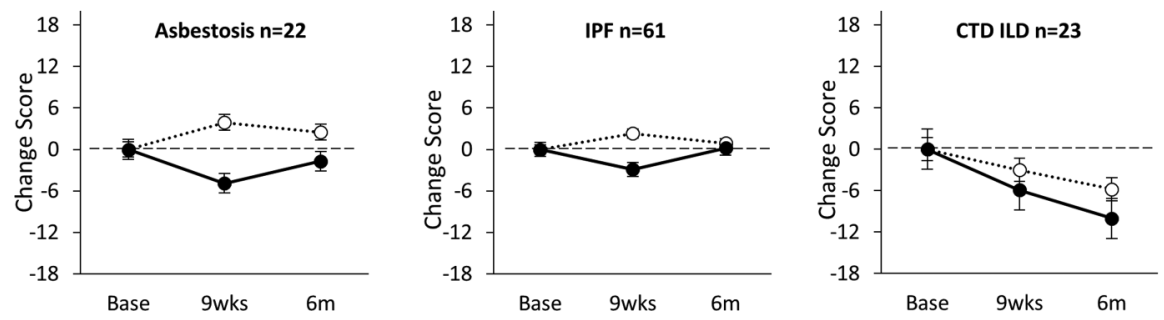

the MID. ${ }^{26}{ }^{28}$ Additionally, aetiology or severity of ILD did not predict short-term improvement in 6MWD or symptoms. This suggests that exercise training may be efficacious across the entire spectrum of disease in achieving short-term improvements.

Patients with high baseline 6MWDs received less benefit following exercise training, consistent with previous studies. ${ }^{15}$ This could be regression to the mean, although the RCT design and ITT analyses would mitigate this effect. ${ }^{31}{ }^{32}$ Alternatively, a ceiling effect of the 6MWT may have masked the efficacy of exercise training in these patients. A ceiling effect has been previously documented in 6MWDs above $450 \mathrm{~m}$ in patients with pulmonary hypertension. ${ }^{33}$ This is consistent with our ROC analysis which identified a baseline 6MWD threshold $\geq 477 \mathrm{~m}$ where exercise training became less effective. Therefore, an alternate measure of functional capacity with a higher ceiling effect such as incremental shuttle walk test ${ }^{34} 35$ may be more sensitive in detecting change in people with high baseline 6MWDs.
Markers of disease severity were the only predictors of 6MWD at 6 months. This is consistent with previous reports ${ }^{14}$ which found greater and more sustained benefits of exercise training in milder disease. As such, engaging in exercise training when the impact of the disease on physiological parameters is milder may assist in preserving benefits. This does not imply that exercise training is ineffective in more severe disease. Our sample, although consisting largely of those with moderate disease, included a wide range of disease severity; yet respiratory or circulatory impairment did not predict short-term benefits. In addition, the baseline threshold beyond which exercise training became ineffective was weak for PASP and indeterminate for FVC. We therefore do not advocate the use of any specific lung function, symptom severity or ROC thresholds to exclude patients from PR. Additionally, patients awaiting lung transplantation, including those with advanced ILD, can achieve gains with $\mathrm{PR},{ }^{36}$ and post-transplant $\mathrm{PR}$ can further improve patients' exercise capacity and functional outcomes. ${ }^{37} 38$ Therefore, all patients with ILD should be provided with the 
Table 4 Between-group differences following the intervention for each subgroup

\begin{tabular}{|c|c|c|c|c|c|c|c|}
\hline & \multicolumn{3}{|l|}{ Mean difference $(95 \% \mathrm{CI})$} & \multicolumn{4}{|l|}{ p Value } \\
\hline & $\begin{array}{l}\text { Asbestosis } \\
n=22\end{array}$ & $\begin{array}{l}\text { IPF } \\
n=61\end{array}$ & $\begin{array}{l}\text { CTD-ILD } \\
n=23\end{array}$ & Group & Time & Subgroup & Group $\times$ Subgroup $\times$ Time \\
\hline \multicolumn{8}{|l|}{ 6MWD (m) } \\
\hline 9 weeks & $68(10$ to 124$)$ & $31(-5$ to 66$)$ & $3(-53$ to 60$)$ & 0.006 & 0.008 & 0.73 & 0.18 \\
\hline 6 months & 92 (36 to 148$)$ & $0.9(-36$ to 38$)$ & $21(-35$ to 77$)$ & & & & \\
\hline \multicolumn{8}{|c|}{ CRDQ Dyspnoea } \\
\hline 9 weeks & $1.5(-3.1$ to 6.2$)$ & $3.1(0.1$ to 6.0$)$ & $2.8(-2.0$ to 7.5$)$ & 0.05 & 0.59 & 0.27 & 0.61 \\
\hline 6 months & $-0.2(-4.9$ to 4.5$)$ & $1.5(-1.5$ to 4.6$)$ & $3.6(-1.1$ to 8.2$)$ & & & & \\
\hline \multicolumn{8}{|l|}{ CRDQ Fatigue } \\
\hline 9 weeks & $4.1(0.4$ to 7.7$)$ & $2.0(-0.3$ to 4.3$)$ & $-0.4(-4.1$ to 3.4$)$ & 0.05 & 0.46 & 0.99 & 0.17 \\
\hline 6 months & $1.4(-2.2$ to 5.1$)$ & $1.1(-1.3$ to 3.5$)$ & $1.8(-1.9$ to 5.4$)$ & & & & \\
\hline \multicolumn{8}{|c|}{ CRDQ Emotion function } \\
\hline 9 weeks & $5.3(-0.5$ to 11.0$)$ & $3.0(-0.7$ to 6.6$)$ & $-0.8(-6.7$ to 5.1$)$ & 0.05 & 0.79 & 0.88 & $0.18 *$ \\
\hline 6 months & $4.6(-1.1$ to 10.4$)$ & $1.2(-2.6$ to5.0) & $1.9(-3.9$ to 7.7$)$ & & & & \\
\hline \multicolumn{8}{|c|}{ CRDQ Mastery } \\
\hline 9 weeks & $4.9(0.4-9.5)$ & 3.7 (0.8 to 6.5$)$ & $-2.0(-6.8$ to 2.6$)$ & 0.07 & 0.05 & 0.99 & $0.005^{*}$ \\
\hline 6 months & $2.2(-2.4$ to 6.8$)$ & $-0.7(-3.7$ to 2.3$)$ & $3.1(-1.5$ to 7.7$)$ & & & & \\
\hline \multicolumn{8}{|c|}{ SGRQ-I Symptoms } \\
\hline 9 weeks & $-19.8(-37.3$ to -3.4$)$ & $-3.9(-13.4$ to 5.6$)$ & $-9.9(-25.4$ to 5.6$)$ & $<0.001$ & 0.67 & 0.03 & 0.50 \\
\hline 6 months & $-19.9(-37.5$ to -3.2$)$ & $-4.7(-14.8$ to 5.4$)$ & $-9.9(-25.1$ to 5.3$)$ & & & & \\
\hline \multicolumn{8}{|c|}{ SGRQ-I Activity } \\
\hline 9 weeks & $-14.6(-30$ to -0.9$)$ & $-7.2(-15.6$ to 1.1$)$ & $0.1(-13.6$ to 13.8$)$ & 0.03 & 0.29 & 0.42 & 0.65 \\
\hline 6 months & $-8.0(-21.4$ to 5.4$)$ & $-3.0(-11.8$ to 5.8$)$ & $-8.2(-21.6$ to 5.2$)$ & & & & \\
\hline \multicolumn{8}{|c|}{ SGRQ-I Impact } \\
\hline 9 weeks & $-7.4(-18.4$ to 3.7$)$ & $-6.4(-13.3$ to 0.5$)$ & $-2.0(-13.2$ to 9.3$)$ & 0.22 & 0.72 & 0.003 & 0.50 \\
\hline 6 months & $0.1(-11.1$ to 10.9$)$ & $0.8(-6.5$ to 8.1$)$ & $-2.7(-13.7$ to 8.4$)$ & & & & \\
\hline \multicolumn{8}{|l|}{ SGRQ-I Total } \\
\hline 9 weeks & $-9.6(-18.3$ to -0.4$)$ & $-5.7(-11.1$ to 0.3$)$ & $-2.8(-11.6$ to 6.0$)$ & 0.01 & 0.78 & 0.004 & 0.56 \\
\hline 6 months & $-5.0(-13.6$ to 3.7$)$ & $-0.8(-6.5$ to 5.0$)$ & $-4.6(-13.3$ to 4.1$)$ & & & & \\
\hline \multicolumn{8}{|c|}{ MMRC Dyspnoea scale } \\
\hline 9 weeks & $-1.0(-1.7$ to -0.3$)$ & $0.009(-0.4$ to 0.5$)$ & $-0.1(-0.8$ to 0.6$)$ & 0.03 & 0.81 & 0.31 & 0.36 \\
\hline 6 months & $-0.7(-1.4$ to -0.005$)$ & $-0.3(-0.8$ to 0.1$)$ & $-0.06(-0.8$ to 0.7$)$ & & & & \\
\hline \multicolumn{8}{|l|}{ UCSD SOBQ } \\
\hline 9 weeks & $-13.5(-27.9$ to 0.9$)$ & $6.5(-2.5$ to 15.6$)$ & $13.5(-1.2$ to 28.2$)$ & 0.94 & 0.23 & 0.31 & 0.13 \\
\hline 6 months & -7.5 ( -21.8 to 6.9$)$ & $-0.2(-9.7$ to 9.2$)$ & $-0.4(-14.9$ to 14.2$)$ & & & & \\
\hline \multicolumn{8}{|c|}{ Knee extensor strength $(\mathrm{kg})$} \\
\hline 9 weeks & $-0.6(-4.1$ to 2.8$)$ & $2.0(-0.1$ to 4.2$)$ & $0.7(-2.7$ to 4.2$)$ & 0.46 & 0.99 & 0.73 & 0.5 \\
\hline 6 months & $-1.8(-5.2$ to 1.5$)$ & $1.0(-1.3$ to 3.3$)$ & $2.1(-1.3$ to 5.5$)$ & & & & \\
\hline \multicolumn{8}{|c|}{ Elbow flexor strength $(\mathrm{kg})$} \\
\hline 9 weeks & $-1.8(-4.1$ to 0.6$)$ & $1.0(-0.5$ to 2.5$)$ & $0.04(-2.3$ to 2.4$)$ & 0.62 & 0.03 & 0.52 & 0.37 \\
\hline 6 months & $-0.2(-2.5$ to 2.2$)$ & $-0.3(-1.8$ to 1.3$)$ & $-0.5(-2.8$ to 1.9$)$ & & & & \\
\hline \multicolumn{8}{|c|}{ 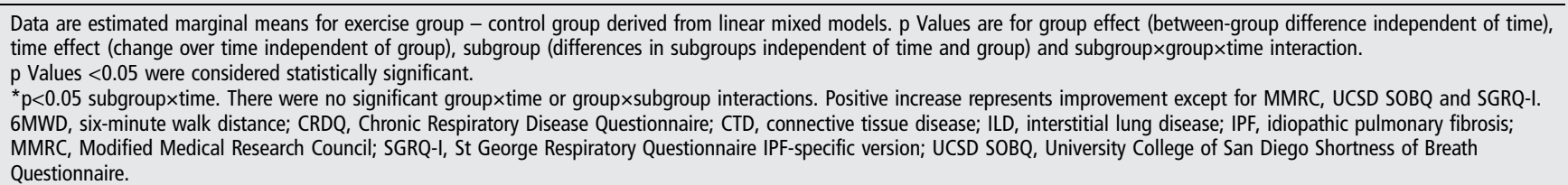 } \\
\hline
\end{tabular}

opportunity to undertake exercise training, although an early referral is recommended to promote longer-lasting effects. Other strategies such as a longer-term intervention, maintenance exercise programmes or recurrent bouts of exercise training may also promote longer-lasting improvements but further research is needed in this important area.

The lack of improvement in 6MWD seen in people with CTD-ILDs was disappointing but could be attributed to the 6MWT's ceiling effect. The CTD-ILD subgroup had higher baseline 6MWDs and a greater percentage of participants above the 6MWD threshold. Additionally, the CTD-ILDs are commonly associated with systemic manifestations such as joint pain, joint swelling, muscle weakness and muscle pain. ${ }^{4}$ Despite some clinically meaningful benefits in HQRoL, there was limited change in majority of outcomes, therefore the standard exercise training principles used in COPD may be less effective in minimising the impact of these systemic manifestations. Other modalities such as hydrotherapy or resistance training may be more suitable in achieving benefits, neither of which has been investigated in ILD or CTD-ILD.

The progression of exercise training loads is crucial if physiological adaptations are to occur. Improvement in exercise 


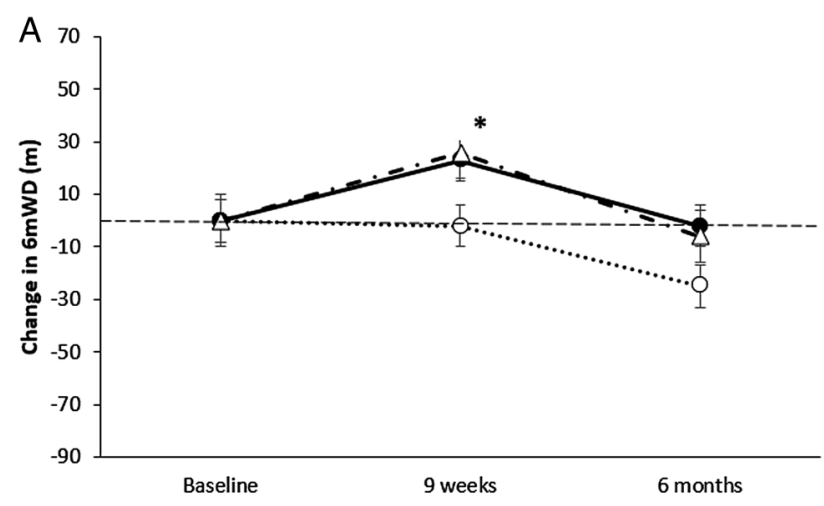

$\ldots \circ \cdots$ Usual Care $\longrightarrow$ Ex Group Intention to treat $-\Delta-$ Ex Group PP Completion

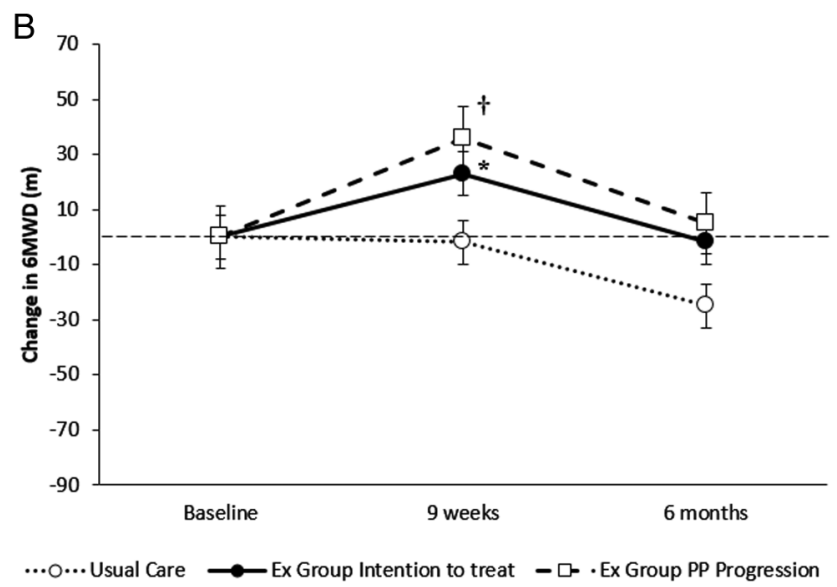

Figure 5 Comparison of change in six-minute walk distance (6MWD) between intention to treat analysis and $(A)$ per-protocol analysis for programme completion; (B) per-protocol analysis for exercise progression. Data are raw mean (SE). ${ }^{*} p<0.05,+p<0.01$, exercise versus control group. PP, per-protocol.

capacity is directly related to training frequency, ${ }^{39}$ with three to five sessions per week being optimal and fewer than two sessions being unlikely to produce meaningful change. ${ }^{39}$ As expected, larger changes in 6MWD were evident in those who attended 12 or more sessions; however successful exercise progression led to much larger changes. This reinforces that exercise training is a critical component of PR for improving functional capacity and HRQoL in ILD. In addition, this suggests that improvements can still be achieved when attendance is less than $75 \%$ if progression of exercise intensity is achieved. There were no significant baseline differences between those who completed the programme or progressed their exercise and those that did not. Therefore, factors such as self-motivation or efficacy, fear of adverse events or comprehension may impact the ability to tolerate exercise training. Further investigation is required in identifying factors that influence non-adherence to exercise progression.

Limited changes were seen in dyspnoea, strength, anxiety and depression. The changes in strength may not have been larger enough to overcome measurement variation between the two raters ${ }^{21}$ or the resistance training may not have been delivered at an adequate intensity to achieve significant changes in strength. ${ }^{39}$ The limited change in anxiety and depression was likely attributed to the low numbers of participants with clinically significant anxiety and depression at baseline. This study may not have been adequately powered to see an effect on
Table 5 Comparison of change in 6MWD between intention to treat and per protocol analyses for each subgroup

\begin{tabular}{|c|c|c|}
\hline & \multicolumn{2}{|c|}{ Mean difference $(95 \% \mathrm{Cl})$} \\
\hline & 9 week follow-up & 6 month follow-up \\
\hline \multicolumn{3}{|l|}{ IPF } \\
\hline ITT $n=29 / 32$ & $31(-5$ to 66$)$ & 0.9 (-36 to 38$)$ \\
\hline PP Completion $n=29 / 15$ & $26(-14$ to 67$)$ & $-18(-63$ to 26$)$ \\
\hline PP Progression $n=29 / 16$ & $55(13-97)$ & $15(-30$ to 60$)$ \\
\hline \multicolumn{3}{|l|}{ Asbestosis } \\
\hline ITT n=11/11 & 68 (10 to 124$)$ & 92 (36 to 148 ) \\
\hline PP Completion $n=11 / 10$ & 75 (19 to 132$)$ & 93 (38 to148) \\
\hline PP Progression $n=11 / 10$ & 75 (19 to 132$)$ & 93 (38 to148) \\
\hline \multicolumn{3}{|l|}{ CTD-ILD } \\
\hline ITT $n=12 / 11$ & $3(-53$ to 60$)$ & $21(-35$ to 77$)$ \\
\hline PP Completion $n=12 / 6$ & $14(-50$ to 78$)$ & $38(-25$ to 101$)$ \\
\hline PP Progression $n=12 / 6$ & $14(-50$ to 78$)$ & $38(-25$ to 101$)$ \\
\hline
\end{tabular}

Values are mean difference (SE). Data are exercise group - control group. $n=$ number of participants in usual care group/exercise training group for the corresponding analysis.

6MWD, six-minute walk distance; CTD, connective tissue disease; ILD, interstitial lung disease; IPF, idiopathic pulmonary fibrosis; ITT, intention to treat; PP, per protocol.

Table 6 Stepwise multiple linear regression model for change in 6MWD following intervention

\begin{tabular}{lrrrrr}
\hline \multicolumn{7}{c}{ B } & SE of $\mathbf{B}$ & $\boldsymbol{\beta}$ & $\mathbf{p}$ Value & $\mathbf{R}^{2}(\%)$ \\
\hline \multicolumn{7}{c}{ Change from baseline to 9 weeks } \\
Constant & 58.468 & 21.572 & & $\mathbf{0 . 0 0 8}$ & \\
Group & 36.595 & 11.722 & -0.296 & $\mathbf{0 . 0 0 2}$ & \\
Baseline 6MWD & -0.141 & 0.045 & 0.297 & $\mathbf{0 . 0 0 2}$ & 15 \\
(m) & & & & & \\
Change from baseline to 6 months & & & & \\
Constant & -12.182 & 36.166 & & 0.737 & \\
PASP (mm Hg) & -1.544 & 0.637 & -0.266 & $\mathbf{0 . 0 1 8}$ & 13 \\
FVC (mL) & 0.021 & 0.010 & 0.224 & $\mathbf{0 . 0 4 4}$ & \\
\hline
\end{tabular}

$\mathrm{p}$ Values $<0.05$ were considered statistically significant. 6MWD, six-minute walk distance; B, unstandardised coefficient; Group, exercise versus usual care with usual care group as reference category; PASP, pulmonary artery systolic pressure; $R^{2}, R$ square-proportion of variation in change in $6 M W D$ explained by the model.

MMRC dyspnoea, or this measure may not be sensitive enough to detect changes following exercise. ${ }^{40}$ Surprisingly the UCSD SOBQ worsened following exercise, except in those with asbestosis, despite improvements beyond the MCID in CRDQ dyspnoea. ${ }^{26}$ Additional research is required to clarify the utility of the UCSD SOBQ in measuring change in dyspnoea in ILD.

This study had some limitations. The 'other ILD' subgroup included a diverse range of diagnoses, however the sample sizes were insufficient to allow detailed subgroup analyses of these entities. Given the small number of participants requiring longterm or exertional oxygen therapy, these results might not be generalisable to those with more advanced disease. Additionally, we did not assess whether the standard education component of $\mathrm{PR}$, which was included in the intervention, was associated with comparable or greater clinical outcomes compared with exercise training alone.

In conclusion, this study demonstrates exercise training is effective for people with ILD and strengthens the rationale for exercise training to be recommended as a standard treatment. 
Magnitude of change is greater in those with asbestosis compared with IPF, but both groups obtain clinically meaningful improvements. Individuals with a range of severity stand to benefit, however longer-lasting effects may occur in milder disease. Progression of exercise intensity and participation in exercise training earlier in the disease course are crucial to optimise and sustain physiological benefits. Further research is needed to determine the optimal exercise training strategy for CTD-ILD and to identify strategies that maximise long-term benefit.

\section{Author affiliations}

'Discipline of Physiotherapy, La Trobe University, Alfred Centre, Prahran, Victoria, Australia

${ }^{2}$ Department of Physiotherapy, Austin Health, Heidelberg, Victoria, Australia ${ }^{3}$ Department of Respiratory \& Sleep Medicine, Austin Health, Heidelberg, Victoria, Australia

${ }^{4}$ Institute for Breathing and Sleep, Heidelberg, Victoria, Australia

${ }^{5}$ Department of Medicine, University of Melbourne, Parkville, Victoria, Australia

${ }^{6}$ Department of Physiotherapy, Alfred Health, Prahran, Victoria, Australia

${ }^{7}$ Department of Physiotherapy, Western Health, Footscray, Victoria, Australia

${ }^{8}$ Allergy, Immunology \& Respiratory Medicine Department, Alfred Health, Melbourne, Victoria, Australia

${ }^{9}$ Department of Medicine, Central Clinical School, Monash University, Melbourne, Victoria, Australia

${ }^{10}$ Department of Respiratory \& Sleep Disorders Medicine, Western Health, Footscray, Victoria, Australia

Acknowledgements The authors would like to acknowledge the contributions of the members of the Respiratory Medicine and Cardiology Departments at Austin Health, Alfred Health and Western Health, who were responsible for conducting the respiratory function tests and the transthoracic echocardiogram and Mr Steve Vander Hoorn and Rachel Sore for their statistical advice. We would like to thank the members of the private respiratory clinics surrounding the Alfred, Austin and Western Hospitals, the Australian IPF registry and Maurice Blackburn and Slater and Gordon Law Firms for their assistance in the distribution of the participant information fliers. We would also like to thank the participants of this study for their time and cooperation.

Contributors LMD, CFM, CJH, IG, NSLG and AEH participated in the conception and design of the study. $L M D, C J H, A L L, K B, C B, A T B$ and RG participated in the acquisition of the data. LMD and AEH completed the data analysis. LMD, CFM, CJH ALL, KB, CB, IG, NSLG, AMS, ATB, RG, AM and AEH drafted and critically revised the manuscript and approved the final version for submission.

Funding LMD received a National Health and Medical Research Council postgraduate scholarship (Grant ID: GNT1017802) and this trial received grant funding from the Pulmonary Fibrosis Foundation/American Thoracic Society Foundation, Institute for Breathing and Sleep and Eirene Lucas Foundation.

Competing interests None declared.

Ethics approval La Trobe University, Alfred Health, Austin Health and Western Health.

Provenance and peer review Not commissioned; externally peer reviewed.

\section{REFERENCES}

1 Demedts M, Wells AU, Anto JM, et al. Interstitial lung disease. An epidemiological overview. Eur Respir J 2001;18:2s-16s.

2 Meyer KC. Diagnosis and management of interstitial lung disease. Trans/ Respir Med 2014;2:4

3 Ahluwalia N, Shea BS, Tager AM. New therapeutic targets in idiopathic pulmonary fibrosis. Aiming to rein in runaway wound healing responses. Am J Respir Crit Care Med 2014;190:867-78.

4 De Lauretis A, Veeraraghavan S, Renzon E. Connective tissue disease-associated interstitial lung disease: how does it differ from IPF? How should the clinical approach differ? Chron Respir Disease 2011;8:53-82.

5 Bradley B, Branley HM, Egan JJ, et al. Interstitial lung disease guideline: The British Thoracic Society in collaboration with the Thoracic Society of Australia and New Zealand and the Irish Thoracic Society. Thorax 2008;63(Suppl 5):v1-58.

6 Raghu G, Collard HR, Egan JJ, et al. An official ATS/ERS/JRS/ALAT statement: idiopathic pulmonary fibrosis: evidence-based guidelines for diagnosis and management. Am J Respir Crit Care Med 2011;183:788-824.

7 Holland AE. Exercise limitation in interstitial lung disease-mechanisms, significance and therapeutic options. Chron Respir Dis 2010;7:101-11.

8 Chang JA, Randall Curtis J, Patrick DL, et al. Assessment of health-related quality of life in patients with interstitial lung disease. Chest 1999;116:1175-82.

9 Behr J, Ryu JH. Pulmonary hypertension in interstitial lung disease. Eur Respir J 2008;31:1357-67.
10 Mendes $\mathrm{P}$, Wickerson $\mathrm{L}$, Helm $\mathrm{D}$, et al. Skeletal muscle atrophy in advanced interstitial lung disease. Respirology 2015;20:953-9.

11 Dowman L, Hill CJ, Holland AE. Pulmonary rehabilitation for interstitial lung disease. Cochrane Database Syst Rev 2014:(10):CD006322.

12 Vainshelboim B, Oliveira J, Yehoshua L, et al. Exercise training-based pulmonary rehabilitation program is clinically beneficial for idiopathic pulmonary fibrosis. Respiration 2014;88:378-88.

13 Dale MT, McKeough ZJ, Munoz PA, et al. Exercise training for asbestos-related and other dust-related respiratory diseases: a randomised controlled trial. BMC Pulm Med 2014;14:180

14 Holland AE, Hill CJ, Glaspole I, et al. Predictors of benefit following pulmonary rehabilitation for interstitial lung disease. Respir Med 2012;106:429-35.

15 Ryerson CJ, Cayou C, Topp F, et al. Pulmonary rehabilitation improves long-term outcomes in interstitial lung disease: a prospective cohort study. Respir Med 2014:108:203-10.

16 Kozu R, Jenkins S, Senjyu $H$. Effect of disability level on response to pulmonary rehabilitation in patients with idiopathic pulmonary fibrosis. Respirology 2011;16:1196-202.

17 Ferreira A, Garvey C, Connors GL, et al. Pulmonary rehabilitation in interstitial lung disease. Benefits and predictors of response. Chest 2009;135:442-7.

18 Dowman L, McDonald CF, Hill C, et al. The benefits of exercise training in interstitial lung disease: protocol for a multicentre randomised controlled trial. BMC Pulm Med 2013;13:8.

19 Dowman L, McDonald CF, Hill CJ, et al. Reliability of the hand held dynamometer in measuring muscle strength in people with interstitial lung disease. Physiotherapy 2016;102:249-55

20 Yorke J, Jones PW, Swigris JJ. Development and validity testing of an IPF-specific version of the St George's Respiratory Questionnaire. Thorax 2010;65:921-6.

21 Eakin EG, Resnikoff PM, Prewitt LM, et al. Validation of a new dyspnea measure. The UCSD Shortness of Breath Questionnaire. Chest 1998;113:619-24.

22 Mahler DA, Harver A, Rosiello R, et al. Measurement of respiratory sensation in interstitial lung disease. Evaluation of clinical dyspnea ratings and magnitude scaling. Chest 1989;96:767-71.

23 Tzanakis N, Maria Samiou T, Lambiri I, et al. Evaluation of health related quality of life and dyspnea scales in patients with idiopathic pulmonary fibrosis. Correlation with pulmonary function tests. Eur J Int Med 2005:16:105-12.

24 Holland AE, Hill CJ, Conron M, et al. Short term improvement in exercise capacity and symptoms following exercise training in interstitial lung disease. Thorax 2008;63:549-54.

25 Holland $A E$, Hill CJ, Conron $M$, et al. Small changes in six-minute walk distance are important in diffuse parenchymal lung disease. Respir Med 2009;103:1430-5.

26 Redelmeier DA, Guyatt GH, Goldstein RS. Assessing the minimal important difference in symptoms: a comparison of two techniques. J Clin Epidemiol 1996;49:1215-19.

27 Zigmond AS, Snaith RP. The hospital anxiety and depression scale. Acta Pscychiatr Scand 1983:67:361-70.

28 Swigris JJ, Brown KK, Behr J, et al. The SF-36 and SGRQ: validity and first look at minimum important differences in IPF. Respir Med 2010;104:296-304.

29 De Torres JP, Pinto-Plata V, Ingenito E, et al. Power of outcome measurements to detect clinically significant changes in pulmonary rehabilitation of patients with COPD. Chest 2002;121:1092-8

30 Nishiyama $\mathrm{O}$, Kondoh $\mathrm{Y}$, Kimura $\mathrm{T}$, et al. Effects of pulmonary rehabilitation in patients with idiopathic pulmonary fibrosis. Respirology 2008;13:394-9.

31 Barnett AG, van der Pols JC, Dobson AJ. Regression to the mean: what it is and how to deal with it. Int I Epidemiol 2005:34:215-20.

32 Suissa S. Lung function decline in COPD trials: bias from regression to the mean. Eur Resp J 2008:32:829-31.

33 Frost $A E$, Langleben $D$, Oudiz $R$, et al. The 6-min walk test (6MWT) as an efficacy endpoint in pulmonary arterial hypertension clinical trials: demonstration of a ceiling effect. Vascul Pharmacol 2005;43:36-9.

34 Spruit MA, Singh SJ, Garvey C, et al., on behalf of the ATS/ERS Task Force on Pulmonary Rehabilitation. An official American Thoracic Society/European Respiratory Society statement: key concepts and advances in pulmonary rehabilitation. Am J Respir Crit Care Med 2013;188:e13-64.

35 Holland AE, Spruit MA, Troosters T, et al. An official European Respiratory Society/ American Thoracic Society technical standard: field walking tests in chronic respiratory disease. Eur Respir J 2014;44:1428-46.

36 Li M, Mathur S, Chowdhury NA, et al. Pulmonary rehabilitation in lung transplant candidates. J Heart Lung Transplant 2013;32:626-32.

37 Wickerson L, Mathur S, Brooks D. Exercise training after lung transplantation: a systematic review. J Heart Lung Transplant 2010;49:457-503.

38 Langer D, Burtin C, Schepers $L$, et al. Exercise training after lung transplantation improves participation in daily activity: a randomized controlled trial. Am J Transplant 2012:12:1584-92.

39 Pollock M, Gaesser GA, Butcher JD, et al. American College of Sports Medicine Position Stand. The recommended quantity and quality of exercise for developing and maintaining cardiorespiratory and muscular fitness, and flexibility in healthy adults. Med Sci Sports Exerc 1998;30:975-91.

40 Jones $\mathrm{P}$, Lareau S, Mahler DA. Measuring the effects of COPD on the patient. Respir Med 2005;99(Suppl B):S11-18. 